\title{
Clinical pharmacology of pyridostigmine and neostigmine in patients with myasthenia gravis
}

\author{
S-M AQUILONIUS, ${ }^{*}$ S-Å ECKERNÄS, * P HARTVIG, B LINDSTRÖM,§ PO OSTERMAN, * \\ E STÅLBERG† \\ From the Departments of Neurology, ${ }^{*}$ Neurophysiology $\dagger$ and Hospital Pharmacy, $\ddagger$ University Hospital, and \\ Department of Drugs, § National Board of Health and Welfare, Uppsala, Sweden
}

SUMMARY Determination of plasma concentration of pyridostigmine in 20 myasthenic patients on maintenance therapy revealed rather small intraindividual variations within a dose interval. The predose concentration varied considerably between different patients and up to seven fold in patients on the same daily dose. No pharmacokinetic interaction between pyridostigmine and neostigmine was found in five patients studied. In six patients the decrement in the deltoid muscle was studied in parallel with determination of the plasma concentrations following administration of pyridostigmine or neostigmine. In these patients the existence of a "bell-shaped" dose response curve is suggested with the maximal effect at a concentration of $30-60 \mathrm{ng} / \mathrm{ml}$ for pyridostigmine and $5-15 \mathrm{ng} / \mathrm{ml}$ for neostigmine.

The introduction of steroids and immunosuppressive drugs in the treatment of myasthenia gravis has not changed the rôle of cholinseterase inhibitors as the basic medical therapy of the disease. Among these drugs pyridostigmine and neostigmine are those commonly prescribed in Sweden. Therapy is in most instances pursued with pyridostigmine but sometimes a combination of the two drugs is used.

The first study on the pharmacokinetics of pyridostigmine using a gas-chromatographic method was published in $1976 .^{1}$ A more selective analytical procedure was developed by Chan et $\mathrm{al}^{2}$ and used in the study of the pharmacokinetics of pyridostigmine $^{3}$ and neostigmine. ${ }^{45}$ With this method, however, it is not possible to measure the two drugs simultaneously. The development of a more sensitive and selective analytical procedure using gas chromatography-mass spectrometry with deuterated internal standards enabled us to study the basic pharmacokinetics of pyridostigmine and neostigmine ${ }^{67}$ The pharmacokinetic profiles of the two drugs were found to be fundamentally similar with a terminal half-life in plasma of about 1.4 and 0.9 hours for pyridostigmine and neostigmine, respec-

Address for reprint requests: Per Olof Osterman, MD, Department of Neurology, University Hospital, S-751 85 Uppsala, Sweden.

Received 15 May 1982 and in revised form 7 March 1983 Accepted 16 April 1983 tively. The oral bioavailability was higher for pyridostigmine $(7.6 \%)$ than for neostigmine $(2 \%)$, which in combination with the longer terminal halflife might offer some pharmacokinetic advantages in maintenance therapy.

The aim of the present study was to elucidate the clinical pharmacology of pyridostigmine and neostigmine in patients with myasthenia gravis. The main objectives have been: (1) to establish the relation between daily dose and steady-state plasma concentration, (2) to investigate if combination therapy with neostigmine and pyridostigmine results in pharmacokinetic interactions, (3) to relate the pharmacokinetics of pyridostigmine and neostigmine to the effect as measured by improvement of decrement of muscle response.

\section{Material and methods}

Blood sampling and analysis of pyridostigmine and neostigmine

Blood samples were collected at regular intervals and immediately cooled on ice and plasma was separated. Two $\mathrm{ml}$ of plasma were transferred to a glass tube and in the case of neostigmine deuterated internal standard $\left(d_{6}-\right.$-neo $)$ was added before the samples were stored in the freezer $\left(-18^{\circ} \mathrm{C}\right)$ to compensate for the in vitro degradation earlier demonstrated. ${ }^{\circ}$

Pyridostigmine and neostigmine were quantitated after ion-pair extraction and determination by gas chromatography-mass spectrometry with chemical ioniza- 
Table 1 Plasma concentrations of cholinesterase inhibitors during maintenance therapy

\begin{tabular}{|c|c|c|c|c|c|c|c|c|}
\hline No & $\begin{array}{l}\text { Age } \\
(y r)\end{array}$ & Sex & $\begin{array}{l}\text { Pyridostigmine } \\
\text { daily dose } \mathrm{mg}\end{array}$ & $\begin{array}{l}\text { Interdose pyridostigmine } \\
\text { concentration range } \\
\text { ng/ml }\end{array}$ & $\begin{array}{l}\text { Neostigmine } \\
\text { daily dose } \\
\text { mg }\end{array}$ & $\begin{array}{l}\text { Interdose neostigmine } \\
\text { concentration range } \\
\text { ng/ml }\end{array}$ & $\begin{array}{l}\text { Atropine } \\
\text { daily dose } \\
\text { mg }\end{array}$ & $\begin{array}{l}\text { Prednisone } \\
\text { alternate day } \\
\text { dose mg }\end{array}$ \\
\hline \multicolumn{9}{|c|}{ A. Patients with ocular and mild generalised myasthenia (1 and $2 A)$} \\
\hline 1 & 73 & $\mathbf{M}$ & $60 \times 6$ & $63-110$ & $15 \times 6$ & 3-5 & $0.5 \times 4$ & \\
\hline 2 & 72 & $\mathbf{F}$ & $120 \times 6$ & 98-115 & & & $0.5 \times 4$ & \\
\hline 3 & 71 & $\mathbf{M}$ & $60 \times 6$ & $32-45$ & & & $0.5 \times 3$ & \\
\hline 4 & 63 & $\mathbf{F}$ & $180 \times 5$ & $210-280$ & & & $0.5 \times 5$ & \\
\hline 5 & 62 & $\mathbf{M}$ & $60 \times 6$ & $59-83$ & & & $0.5 \times 4$ & \\
\hline 6 & 58 & $\mathbf{M}$ & $60 \times 6$ & $51-74$ & & & $0.5 \times 4$ & \\
\hline 7 & 51 & $\mathbf{F}$ & $60 \times 7$ & 57 & $15 \times 6$ & 4 & & \\
\hline 8 & 50 & $\mathbf{F}$ & $60 \times 6$ & $26-44$ & & & & \\
\hline 9 & 39 & $\mathbf{F}$ & $60 \times 6$ & $17-35$ & & & & \\
\hline 10 & 36 & $\mathbf{M}$ & $60 \times 6$ & 39. 54 & & & & \\
\hline 11 & 32 & $\mathbf{F}$ & $120 \times 6$ & $11-40$ & & & $0.5 \times 3$ & \\
\hline 12 & 28 & $\mathbf{F}$ & $60 \times 6$ & $45-74$ & & & $1.0 \times 2$ & \\
\hline $\begin{array}{l}13 \\
14\end{array}$ & $\begin{array}{l}27 \\
25\end{array}$ & $\mathbf{F}$ & $\begin{array}{l}60 \times 6 \\
60 \times 8\end{array}$ & $\begin{array}{l}40-68 \\
64\end{array}$ & & & & \\
\hline \multicolumn{9}{|c|}{ B. Patients with severe generalised myasthenia (2B, 3 and 4$)$} \\
\hline 15 & 83 & $\mathbf{M}$ & $120 \times 6$ & $190-260$ & $15 \times 3$ & not measured & $1.0 \times 1$ & \\
\hline 16 & 71 & $\mathbf{M}$ & $120 \times 6$ & $102-136$ & & & $1.0 \times 3$ & 125 \\
\hline $\begin{array}{l}17 \\
18\end{array}$ & 71 & $\mathbf{M}$ & $\begin{array}{r}60 \times 8 \\
\times 80\end{array}$ & $250-318$ & & & $0.5 \times 3$ & 50 \\
\hline & 68 & $\mathbf{F}$ & $120 \times 6$ & $220-242$ & & & & \\
\hline $\begin{array}{l}19 \\
20\end{array}$ & 36 & $\stackrel{\mathbf{F}}{\mathbf{M}}$ & $\begin{array}{r}60 \times 8 \\
120 \times 6\end{array}$ & $\begin{array}{l}30-68 \\
54-73\end{array}$ & $30 \times 5$ & 4-6 & & \\
\hline
\end{tabular}

tion detection and selected ion monitoring. ${ }^{6 / 7}$ The relative standard deviations in the analysis of $20 \mathrm{ng} / \mathrm{ml}$ of pyridostigmine and neostigmine were 8 and $4 \%$, respectively. The lower detection limits were 5 and $1 \mathrm{ng} / \mathrm{ml}$, respectively.

\section{Patients on maintenance therapy}

Twenty patients with myasthenia gravis were studied during their ordinary oral medication with pyridostigmine. Details of the patients are presented in table 1 . Four patients were on parallel therapy with neostigmine and all except three (Nos 7, 8, 14) were inpatients. The patients were classified by the criteria of Osserman and Oosterhuis ${ }^{8}$ in: ocular and mild generalised (1, 2A) and moderately severe and severe generalised $(2 \mathrm{~B}, 3,4)$ forms of myasthenia. The latter group comprised six patients but at the time of the investigation three of these $(15,17,20$, table 1$)$ had mild symptoms only, due to treatment. Three patients were treated with prednisone on alternate days and 11 used atropine. Eleven patients had additional medication such as antacids $(n=4)$, thiazide diuretics $(n=4)$, digitalis $(n=3)$, sulphonylureas $(n=3)$ and phenytoin $(n=2)$.

Interaction between neostigmine and pyridostigmine In five patients a possible pharmacokinetic interaction between the two drugs was investigated. The patients were given oral neostigmine on several occasions for at least one day and on the next day five blood samples were collected regularly during a dosage interval. Thereafter the two drugs were administered together for three days and blood samples were taken as above. Neostigmine was then withdrawn and the patients were treated with pyridostigmine only. After one to three days a new series of blood samples was taken during a dosage interval. In the investigation period no other medications were given.
Decrement of muscle response at repetitive nerve stimulation

In six patients the improvement of decrement was studied after administration of pyridostigmine $5-6 \mathrm{mg}$ iv $(\mathrm{n}=3)$, neostigmine $0.5-1.5 \mathrm{mg}$ iv $(\mathrm{n}=5)$ or neostigmine $30 \mathrm{mg}$ orally $(n=1)$. The patients had more than $25 \%$ decrement in the deltoid muscle and had not been treated with cholinesterase inhibitors previously.

The investigation was performed in the morning before the patients had left the bed or with the patients seated in a comfortable chair after minimal preceeding exercise. The patients rested completely for $60 \mathrm{~min}$ before the drug was given. Throughout the investigation a thermostatically controlled heating lamp was used to keep a constant skin temperature of $32^{\circ} \mathrm{C}$.

Recording of the muscle response was made with surface electrodes, one over the midpoint of the deltoid muscle, the other over the acromion. Stimulation was made with surface electrodes over Erb's point with a stimulation strength set to $25 \%$ above that giving maximal amplitude, with a duration of $0 \cdot 1 \mathrm{~ms}$ and a frequency of $2 \mathrm{~Hz}$. By means of a computer (LSI 11/23) the negative amplitude and area under the whole signal was measured. The relative difference between the first and the fourth response was measured for these two parameters. The area measurement was added as a test of the recording quality. Normally the two parameters show a good correlation but in cases of artifacts they usually differ and the test has to be repeated. In the following only the amplitude results will be given. Measurements were made every tenth minute during 30-60 minutes before the administration of the drugs and then every fifth minute after intravenous and every tenth minute after oral administration for another 3 to 5 hours. 
Pharmacokinetic analysis

A polyexponential equation was used to fit the plasma concentration-time data by using the computer program ESTRIP.' The area under the curve was calculated by the trapezoidal rule and extrapolated to infinite time. The absolute oral biological availability was estimated approximately by comparison of the dose corrected areas under the curves with the iv data.

\section{Results}

\section{PLASMA CONCENTRATIONS DURING} MAINTENANCE THERAPY

Pyridostigmine The plasma concentration of pyridostigmine within a dose interval did not show large intraindividual variations (table 1). However, on the same daily dose the interindividual variations were 4-7 fold (tables 1 and 2). The mean daily dose was somewhat higher in the older patients $(>60$ years) than in the younger group (table 3 ). The predose plasma concentration of pyridostigmine was also higher in the older patients $(p<0.01)$. In this group severe generalised myasthenia was more frequent (tables 1 and 3).

In the 11 patients concomitantly treated with atropine the mean maximal plasma concentration was significantly higher $(139 \pm 30, \mathrm{n}=11)$ than in the patients not treated with atropine $(78 \pm 26$, $\mathrm{n}=9$ ).

In the three patients on prednisone the plasma concentration of pyridostigmine did not seem to differ from that in other patients on the same daily dose of pyridostigmine. Influences of the other medications are difficult to assess but there were no apparent systematic variations.

Neostigmine Four patients were treated simultaneously with neostigmine and pyridostigmine and the plasma concentration of neostigmine ranged from $3-6 \mathrm{ng} / \mathrm{ml}$.

Table 2 Plasma concentrations of pyridostigmine after different daily doses

\begin{tabular}{|c|c|c|}
\hline $\begin{array}{l}\text { Mean daily dose, } \\
\text { mg }\end{array}$ & $\begin{array}{l}\text { No of } \\
\text { patients }\end{array}$ & $\begin{array}{l}\text { Mean interdose range of } \\
\text { pyridostigmine, plasma } \\
\text { concentration ng/ml }( \pm S E)\end{array}$ \\
\hline $\begin{array}{l}360 \\
480 \\
720 \\
900\end{array}$ & $\begin{array}{l}9 \\
3 \\
6 \\
1\end{array}$ & 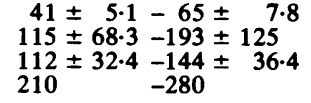 \\
\hline
\end{tabular}

INTERACTION BETWEEN NEOSTIGMINE AND PYRIDOSTIGMINE

The mean interdose plasma concentration of pyridostigmine and neostigmine during a dosage interval in five patients given each drug alone and in combination can be seen in table 4 . The mean pyridostigmine plasma concentrations were almost identical on the two occasions. Similarly, the mean neostigmine plasma concentration was not significantly changed when the drug was given together with pyridostigmine.

\section{PHARMACOKINETIC ANALYSES OF SINGLE-DOSE} DATA

The results are shown in table 5. For the iv data the best fit was a biexponential equation. The total plasma clearance was slightly higher for pyridostigmine $(1.0 \mathrm{~V} /$ (hours.kg)) than for neostigmine $(0.91$ $1 /($ hours.kg)) and was similar to the values observed in our earlier studies. ${ }^{67}$ The mean terminal half-life for pyridostigmine was 1.05 hours and for neostigmine 0.77 hours. However, there was a rather large interindividual variation for neostigmine. In the three patients where the pharmacokinetics of both drugs were studied the half-life for pyridostigmine was significantly longer ( 1.05 hours) as compared to neostigmine $(0.48$ hours). In the patient studied the bioavailability after oral administration of neostigmine was estimated to $2 \%$, a figure earlier found. ${ }^{6}$

\section{RELATIONSHIP BETWEEN PLASMA}

CONCENTRATIONS AND MUSCLE DECREMENT

Following iv injection of pyridostigmine and neostigmine a rapid decrease in muscular decrement occurred with a maximal effect after about 15 minutes. Typical experiments are shown in fig 1 (ad). In most cases the maximal effect on decremental response remained relatively unchanged for 1-2 hours. Only one patient (GA) could manage to take part during the six hours experimental time needed to await a complete restoration of the decrement to the preinjection level.

In fig $3(a-c)$ the log plasma concentrations versus the effect on the decrement (moving averages) are shown. As can be seen there was a direct linear relation between log plasma concentration and effect only for the oral data (figs $2,3 \mathrm{c}$ ) while the iv data are more complex. A positive linear correlation (nega-

Table 3 Plasma concentrations of pyridostigmine in different age groups

\begin{tabular}{llll}
\hline $\begin{array}{l}\text { Age group no of } \\
\text { patients }\end{array}$ & $\begin{array}{l}\text { Daily dose of pyridostigmine } \\
m g \text { (mean } \pm S E)\end{array}$ & $\begin{array}{l}\text { Predose plasma concentration } \\
\text { ng/ml (mean } \pm S E)\end{array}$ & $\begin{array}{l}\text { No of patients with severe } \\
\text { myasthenia }\end{array}$ \\
\hline$<60 \mathrm{n}=10$ & $450 \pm 146$ & $49 \cdot 3 \pm 14 \cdot 5$ \\
$>60 \mathrm{n}=10$ & $582 \pm 196$ & $142 \cdot 3 \pm 95 \cdot 4^{*}$ & 1 \\
\hline
\end{tabular}

*= significantly higher $(p<0.01)$ than in the age group $<60$ years of age 
Table 4 Interaction between neostigmine and pyridostigmine

\begin{tabular}{lcc}
\hline & \multicolumn{2}{c}{ Mean interdose plasma concentration (mean $\pm S E, n g / m l, n=5)$} \\
\cline { 2 - 3 } Drug & Monotherapy & Combination therapy \\
\hline Neostigmine & $2.5 \pm 1 \cdot 5$ & $3.6 \pm 1.3$ \\
Pyridostigmine & $51.8 \pm 21.0$ & $50.4 \pm 27.5$ \\
\hline
\end{tabular}

Table 5 Pharmacokinetic analyses

\begin{tabular}{|c|c|c|c|c|c|c|c|c|}
\hline Patient & Drug & $\begin{array}{l}\text { Dose } \\
\text { mg/case }\end{array}$ & $r^{2}$ & $\begin{array}{c}t 1 / 2 \\
(h r)\end{array}$ & $K_{A}$ & $\begin{array}{l}\text { AUC } \\
\left(h r . n g \cdot m l^{-1}\right)\end{array}$ & $\underset{\left(1 \cdot \mathrm{kg}^{-1}\right)}{V d}$ & $\begin{array}{l}\mathrm{Cl} \\
\left(1 \cdot h r^{-1} \cdot k g^{-1}\right)\end{array}$ \\
\hline $\begin{array}{l}\text { GA } \\
\text { KL } \\
\text { MB } \\
\text { MEAN } \pm \text { SE }\end{array}$ & $\begin{array}{l}\text { pyr } \\
\text { pyr } \\
\text { pyr } \\
\text { pyr }\end{array}$ & $\begin{array}{ll}5 & \text { /iv } \\
5 & \text { /iv } \\
6 & / \mathrm{iv} \\
- & \end{array}$ & $\begin{array}{l}0.999 \\
0.995 \\
0.988 \\
-\end{array}$ & $\begin{array}{l}0.76 \\
0.70 \\
1.7 \\
1.05 \pm 0.32\end{array}$ & $\bar{z}$ & $\begin{array}{l}74 \\
61 \\
80\end{array}$ & $\begin{array}{l}1 \cdot 23 \\
1.20 \\
2.85 \\
1.76 \pm 0.54\end{array}$ & $\begin{array}{l}0.97 \\
0.87 \\
1.15 \\
1.0 \pm 0.08\end{array}$ \\
\hline $\begin{array}{l}\text { GA } \\
\text { KL } \\
\text { MB } \\
\text { MÖ* } \\
\text { ME } \\
\text { MW } \\
\text { MEAN } \pm \text { SE }\end{array}$ & $\begin{array}{l}\text { neo } \\
\text { neo } \\
\text { neo } \\
\text { neo } \\
\text { neo } \\
\text { neo } \\
\text { neo }\end{array}$ & $\begin{array}{l}1 \cdot 5 / \mathrm{iv} \\
1 \cdot 5 / \mathrm{iv} \\
1 \cdot 5 / \mathrm{iv} \\
1 \cdot 0 / \mathrm{iv} \\
1 \cdot 5 / \mathrm{iv} \\
0 \cdot 5 / \mathrm{iv} \\
-\end{array}$ & $\begin{array}{l}0.999 \\
0.998 \\
0.998 \\
0.993 \\
0.929 \\
0.993 \\
-\end{array}$ & $\begin{array}{l}0.42 \\
0.40 \\
0.62 \\
0.78 \\
1.95 \\
0.42 \\
0.77 \pm 0.24\end{array}$ & $\begin{array}{l}= \\
= \\
=\end{array}$ & $\begin{array}{r}49 \\
29 \\
17 \\
12 \\
64 \\
7 \\
-\end{array}$ & $\begin{array}{l}0.26 \\
0.41 \\
1.35 \\
1.51 \\
1.0 \\
1.0 \\
0.92 \pm 0.2\end{array}$ & $\begin{array}{l}0.43 \\
0.72 \\
1.50 \\
1.33 \\
0.36 \\
1.1 \\
0.91 \pm 0.19\end{array}$ \\
\hline UN & neo & $30 /$ orally & 0.930 & 1.7 & 1.57 & 24 & $0.9 \dagger$ & $0.89 \dagger$ \\
\hline
\end{tabular}

*In this patient muscle decrement was not determined tCompensated for the oral bioavailability

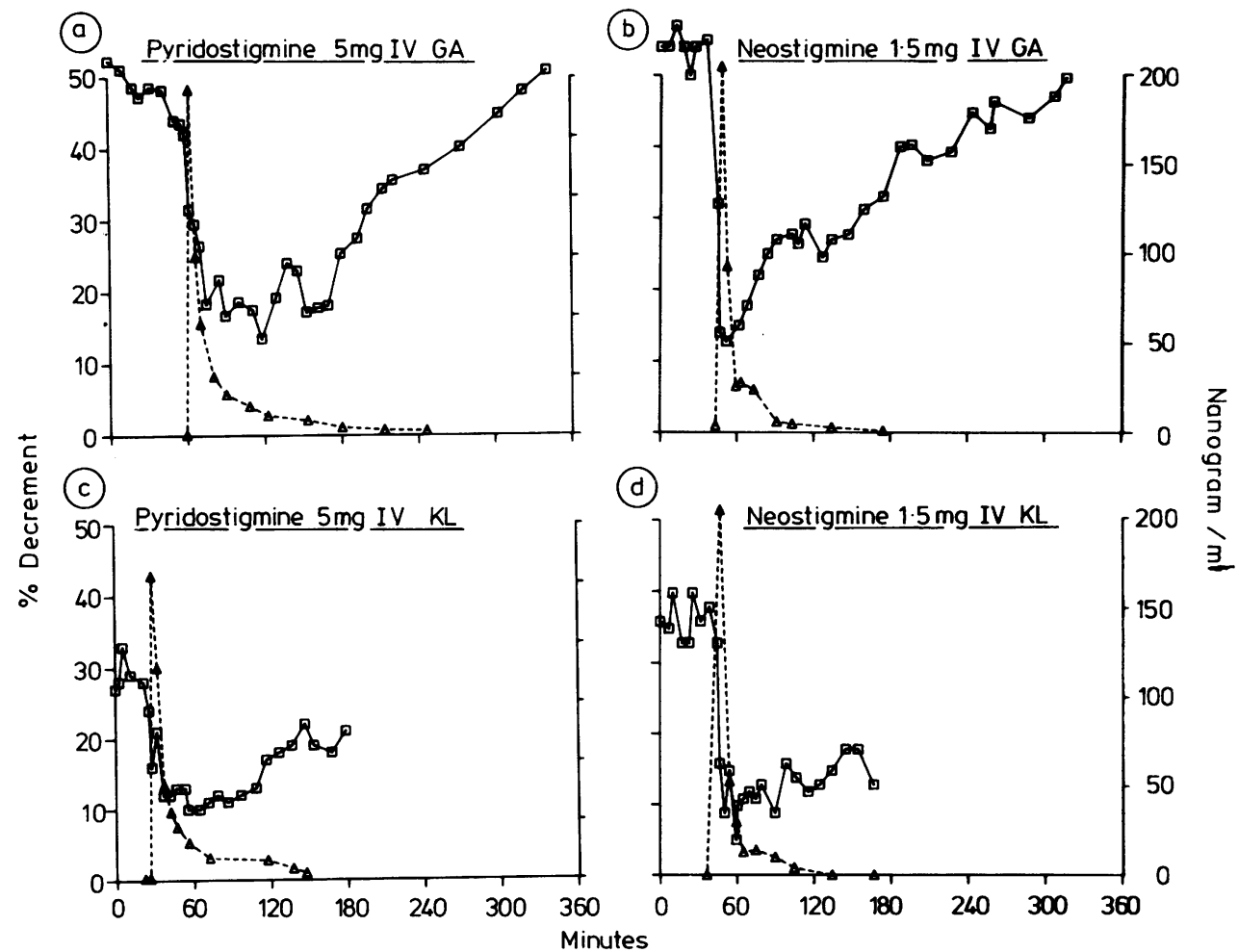

Fig 1 a $-\mathrm{d}$ Plasma concentrations ( $\Delta----\Delta$ ) of cholinesterase inhibitor and muscular decrement $(\square-\square)$ following pyridostigmine or neostigmine iv to two myasthenic patients (GA and $K L)$. 


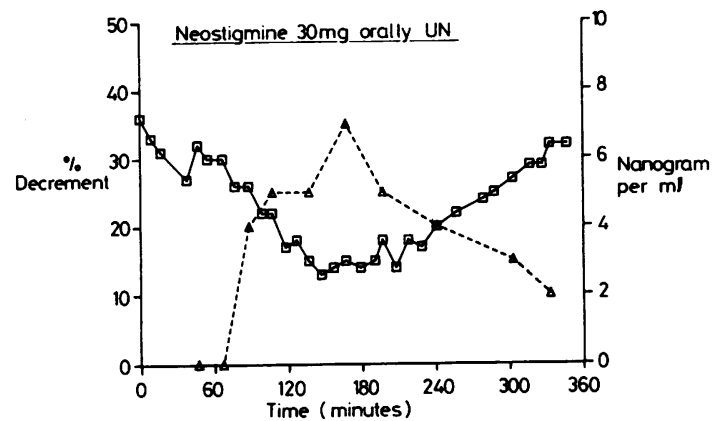

Fig 2 Neostigmine plasma concentrations $(\Delta----\Delta)$ and muscular decrement ( $\square-\square)$ following $30 \mathrm{mg}$ neostigmine orally. tive slope) between log plasma concentration following iv injection and effect is seen when the plasma concentration is lower than $30-60 \mathrm{ng} / \mathrm{ml}$ for pyridostigmine and about $5-15 \mathrm{ng} / \mathrm{ml}$ for neostigmine. Higher concentrations give a negative correlation (positive slope) between plasma concentration and effect on muscle decrement. In one patient (ME, fig $3 b$ ) with a low clearance of neostigmine there was a negative correlation still after 3.5 hours; at this time the plasma concentration was above $6 \mathrm{ng} / \mathrm{ml}$. In one patient (GA, fig 3b) maximal effect on decrement was seen at a very high plasma concentration of neostigmine $(100 \mathrm{ng} / \mathrm{ml})$, whereas following pyridostigmine the corresponding effect was seen at a plasma concentration similar to what was found in the other patients.

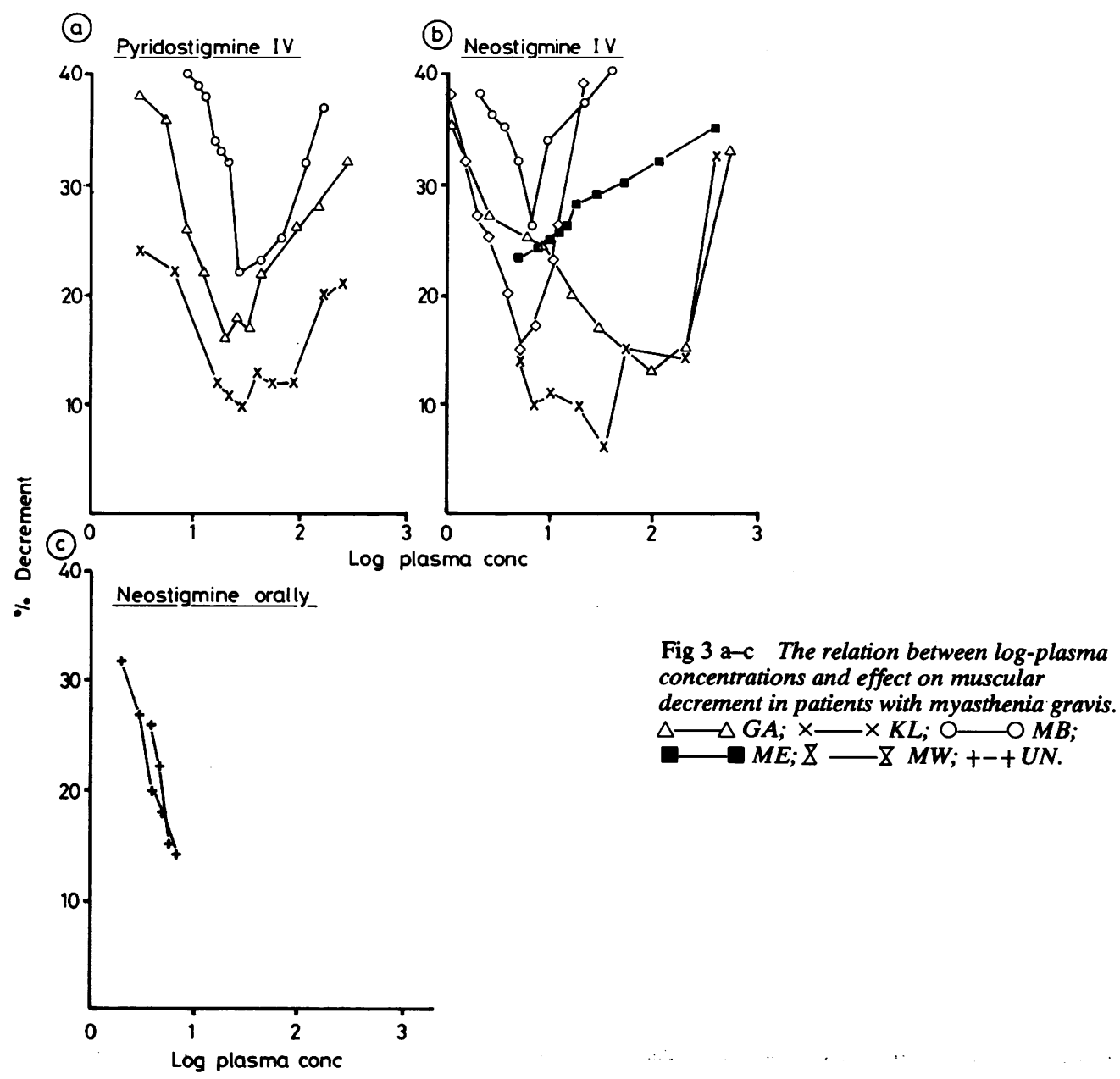




\section{Discussion}

PLASMA CONCENTRATION DURING MAINTENANCE THERAPY

On maintenance therapy with pyridostigmine the intraindividual variations in plasma concentration of the drug were rather small during a 3 hour dose interval. This is in agreement with results earlier obtained. ${ }^{7}$ The limited variation in steady-state concentration of pyridostigmine in spite of the short half-life is probably explained by the slow absorption from the gastrointestinal tract earlier shown. ${ }^{7}$ Much larger variations in pyridostigmine concentration during a dose interval have been reported ${ }^{10}$ and an enterohepatic circulation has been postulated due to an observed second peak in the plasma concentration curve. In the present study no such phenomenon was seen. In view of the lag-time together with food intake" the "second peak" may be the plasma concentration peak of the tablet before.

The interindividual differences in steady-state plasma concentration of pyridostigmine between myasthenic patients on maintenance therapy were considerable (table 1) which is in agreement with earlier reports. ${ }^{710}$ The interindividual variations were larger and the predose plasma concentrations higher in the older patients who had a higher mean daily dose (table 3 ). The relation between dose and plasma concentration is, however, complex and the possible influence of a number of factors as, for example, age, severity of disease, impaired kidney function and other medications cannot be determined in any detail due to the relatively small number of patients. It is known that pyridostigmine is predominantly eliminated in the urine and a decreased renal function could lower the total clearance of the drug. ${ }^{11-13}$ In the older age group more severe forms of the disease were found (tables 1 and 2) which may explain the use of higher doses of cholinesterase inhibitors. This is in accordance with the findings of White et $a^{10}$ who observed higher plasma concentrations of pyridostigmine in "poorly controlled patients" than in "well controlled".

\section{EFFECT OF OTHER DRUGS}

It has earlier been shown that the oral bioavailability of pyridostigmine is decreased in patients on steroids $^{10}$ but in the present investigation no influence of steroid therapy could be seen. Chan and Calvey ${ }^{12}$ suggested that a competition for the renal excretion could exist between pyridostigmine and basic drugs. In our patients treated with atropine the mean maximal plasma concentration of pyridostigmine was much higher than in patients not taking atropine. This is probably not a result of phar- macokinetic interaction but of increased need for anticholinergic therapy in patients having higher plasma concentration of pyridostigmine and thus more side-effects.

The plasma concentrations of neostigmine are in the same range (3-6 $\mathrm{ng} / \mathrm{ml})$ as earlier reported following 90-150 mg orally. ${ }^{6}$ Theoretically the simultaneous therapy with neostigmine and pyridostigmine could give rise to drug-drug interactions during absorption, or by competition for enzymatic degradation or renal secretion as has been postulated. ${ }^{12} 14$ In the present study no pharmacokinetic interaction could be detected.

\section{PHARMACOKINETIC DATA}

There were rather large interindividual variations in clearance and terminal half-lives of pyridostigmine and neostigmine. The mean half-lives of the two drugs did not differ significantly. In the crossover experiment (patients GA, KL and MB), however, there was a 2:1 relation between the half-life of pyridostigmine (1.05 hours) compared with neostigmine ( 0.48 hours) while the total clearance was similar. This is explained by the much lower volume of distribution for neostigmine $(0.67 \mathrm{l} / \mathrm{kg})$ compared with pyridostigmine $(1.76 \mathrm{l} / \mathrm{kg})$. The results are similar to those earlier found. ${ }^{67}$

The rationale of parallel therapy with pyridostigmine and neostigmine with very much the same pharmacodynamic and pharmacokinetic profile could be questionable. The higher oral bioavailability and the slightly longer terminal half-life favour the use of pyridostigmine as monotherapy.

\section{DOSE-EFFECT STUDIES}

A previous study of nine myasthenic patients who were examined neurologically at $1 / 2$ hour intervals after administration of oral pyridostigmine showed improved motor performance which in most patients seemed to be positively related to the time-course of pyridostigmine plasma concentration." However, clinical evaluation of the effect involves many problems; for example standardised tests of power and fatigue in several muscles are time consuming and necessitate rather long rest between each examination. Furthermore, myasthenic weakness typically varies considerably between different muscle groups in the same patient and may be restricted to a few muscles. A certain dose of anticholinesterase may improve function of some muscles but not others. The difficulties encountered in these types of studies were recently illustrated by. Davison et $a l^{15}$ who found that only two out of nine myasthenic patients on their normal drug regime showed a significant correlation between plasma levels of pyridostigmine and a global evaluation of muscle functions. 
Determinations of muscle decrement only assess the function in a single muscle and can only be preformed in selected patients with a pathological decrement in this muscle. A positive correlation between the plasma concentrations of pyridostigmine and the decremental response in the adductor pollicis has previously been reported in four myasthenic patients on their normal drug regime. ${ }^{16}$

In the present study there was a linear relation between log-plasma concentration and effect on muscle decrement in the range $5-30 \mathrm{ng} / \mathrm{ml}$ after iv administration of pyridostigmine and 1 to about $10 \mathrm{ng} / \mathrm{ml}$ after oral and iv administration of neostigmine (fig $3 \mathrm{a}-\mathrm{c}$ ). At higher concentration the effect declined with increasing plasma concentrations suggesting "bell-shaped" dose response curves. This interpretation is in agreement with the findings by Stålberg et al. ${ }^{17}$ In single muscle fibre recordings some fibres responded with an increased blocking of the action potential when higher doses of edrophonium were administered, while lower doses had the opposite effect. On the other hand, it must be realised that high plasma concentrations were measured (figs 1-3) mainly in the distribution phase of the cholinesterase inhibitors implying that an equilibrium between plasma and effector compartment was not attained. Some support for the existence of a "bell-shaped" dose response curve is obtained from the "low clearance patient", ME. In this patient there was still a negative correlation between plasma concentration of neostigmine and effect after 3.5 hours.

The interindividual differences in steady-state plasma concentration of neostigmine and pyridostigmine in patients on "optimal" therapy are considerable and our results do not at present support the existence of a generally useful "therapeutic interval". However, there is a striking difference between the rather low plasma concentrations of pyridostigmine which give maximal effect on the decrement in previously untreated patients and the steady-state concentrations in some patients on their ordinary daily dose. Although the effect on decrement may not equal the global clinical effect, it seems important to analyse further dose-effect relationships by examining the muscle decremental response during infusion experiments, permitting the establishment of different steady-state levels of the cholinesterase inhibiting drug in the same myasthenic patient.

The study was partly supported by the Swedish Medical Research Council (grant 135 and 4373) and the Swedish Society of Medical Sciences.
References

${ }^{1}$ Cohan SL, Pohlmann JLW, Mikszewski J, O'Doherty DS. The pharmacokinetics of pyridostigmine. Neurology (Minneap) 1976;26:536-9.

${ }^{2}$ Chan K, Williams NE, Baty JD, Calvey TN. A quantitative gas-liquid chromatographic method for the determination of neostigmine and pyridostigmine in human plasma. J Chromatography 1976;120:349-58.

${ }^{3}$ Calvey TN, Chan K. Plasma pyridostigmine levels in patients with myasthenia gravis. Clin Pharmacol Ther 1977;21:187-93.

4 Williams NE, Calvey TN, Chan K. Clearance of neostigmine from the circulation during the antagonism of neuromuscular block. $\mathrm{Br} J$ Anaesth 1978;50:1065-7.

s Somani SM, Chan K, Dehghan A, Calvey TN. Kinetics and metabolism of intramuscular neostigmine in myasthenia gravis. Clin Pharmacol Ther 1980;28:64-8.

6 Aquilonius S-M, Eckernäs S- $\AA$, Hartvig P, Hultman J, Lindström B, Osterman PO. A pharmacokinetic study of neostigmine in man using gas chromatographymass spectrometry. Eur J Clin Pharmacol 1979;15:367-71.

${ }^{7}$ Aquilonius S-M, Eckernäs S- $\AA$, Hartvig P, Lindström B, Osterman PO. Pharmacokinetics and oral bioavailability of pyridostigmine in man. Eur J Clin Pharmacol 1980;18:423-8.

${ }^{8}$ Oosterhuis HJGH. Studies in myasthenia gravis. Part 1. A clinical study of 180 patients. J Neurol Sci 1964;1:512-46.

${ }^{9}$ Brown RD, Manno JE. ESTRIP a basic computer program for obtaining initial polyexponential parameters estimates. J Pharmacol Sci 1978;67:1687-91.

${ }^{10}$ White MC, De Silva P, Havard CWH. Plasma pyridostigmine levels in myasthenia gravis. Neurology $(\mathrm{Ny})$ 1981;31:145-50.

${ }^{11}$ Kornfeld P, Samuels AJ, Wolf RL, Osserman KE. Metabolism of ${ }^{14} \mathrm{C}$-labeled pyridostigmine in myasthenia gravis. Evidence for multiple metabolites. Neurology (Minneap) 1970;20:634-41.

${ }^{12}$ Chan K, Calvey TN. Renal clearance of pyridostigmine in patients with myasthenia gravis. Eur Neurol 1977;16:69-72.

${ }^{13}$ Cronnelly R, Stanski DR, Miller RD, Sheiner LB. Pyridostigmine kinetics with and without renal function. Clin Pharmacol Ther 1980;28:78-81.

${ }^{14}$ Chan K, Davison SC, Dehghan A, Hyman N. The effect of neostigmine on pyridostigmine bioavailability in myasthenic patients after oral administration. Meth Find Exptl Clin Pharmacol 1981;3:291-6.

15 Davison SC, Hyman NM, Dehghan A, Chan K. The relationship of plasma levels of pyridostigmine to clinical effect in patients with myasthenia gravis. $J$ Neurol Neurosurg Psychiatry 1981;44:1141-5.

${ }^{16}$ Chan K, Calvey TN. Plasma concentration of pyridostigmine and effects in myasthenia gravis. Clin Pharmacol Ther 1978;22:596-601.

${ }^{17}$ Stålberg E, Trontelj JV, Schwartz MS. Single-muscle-fiber recording of the jitter phenomena in patients with myasthenia gravis and in members of their families. Ann NY Acad Sci 1976;274:189-202. 